\title{
Reliability and validity of the Patient Benefit Assessment Scale for Hospitalised Older Patients (P-BAS HOP)
}

\author{
Maria Johanna van der Kluit ${ }^{1 *}$, Geke J. Dijkstra ${ }^{2,3}$ and Sophia E. de Rooij ${ }^{1,4}$
}

\begin{abstract}
Background: The Patient Benefit Assessment Scale for Hospitalised Older Patients (P-BAS HOP) is a tool which is capable of both identifying the priorities of the individual patient and measuring the outcomes relevant to him/her, resulting in a Patient Benefit Index (PBI) with range $0-3$, indicating how much benefit the patient had experienced from the admission. The aim of this study was to evaluate the reliability, validity, responsiveness and interpretability of the P-BAS HOP.
\end{abstract}

Methods: A longitudinal study among hospitalised older patients with a baseline interview during hospitalisation and a follow-up by telephone 3 months after discharge. Test-retest reliability of the baseline and follow-up questionnaire were tested. Percentage of agreement, Cohen's kappa with quadratic weighting and maximum attainable kappa were calculated per item. The PBI was calculated for both test and retest of baseline and follow-up and compared with Intraclass Correlation Coefficient (ICC). Construct validity was tested by evaluating pre-defined hypotheses comparing the priority of goals with experienced symptoms or limitations at admission and the achievement of goals with progression or deterioration of other constructs. Responsiveness was evaluated by correlating the PBI with the anchor question 'How much did you benefit from the admission?'. This question was also used to evaluate the interpretability of the PBI with the visual anchor-based minimal important change distribution method.

Results: Reliability was tested with 53 participants at baseline and 72 at follow-up. Mean weighted kappa of the baseline items was 0.38 . ICC between PBI of the test and retest was 0.77 .

Mean weighted kappa of the follow-up items was 0.51 . ICC between PBI of the test and retest was 0.62 .

For the construct validity, tested in 451 participants, all baseline hypotheses were confirmed. From the follow-up hypotheses, tested in 344 participants, five of seven were confirmed.

The Spearman's correlation coefficient between the PBI and the anchor question was 0.51 .

The optimal cut-off point was 0.7 for 'no important benefit' and 1.4 points for 'important benefit' on the PBI.

Conclusions: Although the concept seems promising, the reliability and validity of the P-BAS HOP appeared to be not yet satisfactory. We therefore recommend adapting the P-BAS HOP.

Keywords: Older adults, Hospitalisation, Patient perspective, Goal setting, Patient-reported outcomes, Validity, Reliability, Responsiveness, Minimal important change (MIC), Value-based health care

\footnotetext{
*Correspondence: m.j.van.der.kluit@umcg.nl

'University of Groningen, University Medical Center Groningen, University

Center for Geriatric Medicine, Hanzeplein 1, 9700, RB, Groningen, The

Netherlands

Full list of author information is available at the end of the article
}

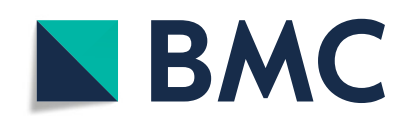

(c) The Author(s). 2021 Open Access This article is licensed under a Creative Commons Attribution 4.0 International License, which permits use, sharing, adaptation, distribution and reproduction in any medium or format, as long as you give appropriate credit to the original author(s) and the source, provide a link to the Creative Commons licence, and indicate if changes were made. The images or other third party material in this article are included in the article's Creative Commons licence, unless indicated otherwise in a credit line to the material. If material is not included in the article's Creative Commons licence and your intended use is not permitted by statutory regulation or exceeds the permitted use, you will need to obtain permission directly from the copyright holder. To view a copy of this licence, visit http://creativecommons.org/licenses/by/4.0/. The Creative Commons Public Domain Dedication waiver (http://creativecommons.org/publicdomain/zero/1.0/) applies to the data made available in this article, unless otherwise stated in a credit line to the data. 


\section{Background}

Healthcare interventions are often evaluated in terms of survival or disease-specific measures, while for many older people more personal goals such as functional status, social functioning and relief of symptoms, which are considered important by the individual self, are prioritised [1, 2]. Furthermore, which outcomes are considered important differ per individual $[1,3]$. When care is to be systematically evaluated by personal goal-oriented outcomes, a tool is needed which is capable of both identifying the priorities of the individual patient and measuring the outcomes relevant to him/her. We therefore developed the $\mathrm{Pa}$ tient Benefit Assessment Scale for Hospitalised Older Patients (P-BAS HOP) [4].

The P-BAS HOP is an interview-based tool consisting of two parts: 1) a baseline questionnaire to select and assess the importance of various predefined goals, based on subjects derived from qualitative interviews with hospitalised older patients and 2) an evaluation questionnaire to evaluate the extent to which the hospital admission helped to achieve these individual goals. Based on these data it is possible to compute an individual Patient Benefit Index. The comprehensibility, feasibility and a first indication of content validity were already tested in pilot test and field tests [4]. The aim of the present study is to evaluate the reliability, validity, responsiveness and interpretability of the P-BAS HOP.

\section{Methods}

\section{Design and population}

This longitudinal study was performed among hospitalised older patients. The first face-to-face interview took place within the first 4 days of hospitalisation. The follow-up interview was performed 3 months after discharge by telephone.

Eligible participants were 70 years and older; had either a planned or unplanned hospital admission on medical or surgical wards of a university teaching hospital in the Netherlands, had an expected hospital stay of at least $48 \mathrm{~h}$; were able to speak and understand Dutch and were without cognitive impairment. Inclusion criteria were verified with the staff nurse. Patients were approached by a trained research assistant and gave signed informed consent.

\section{Questionnaire: P-BAS HOP}

The P-BAS HOP is an interview-based questionnaire. The baseline questionnaire consists of two parts: in the first part the interviewer lists subjects and the participant can indicate whether experiencing or expecting limitations regarding that subject. In the second part, the participant is asked, for each subject identified in the first part whether it is a goal for the current hospitalisation and, if so, how important the goal is. Answer options are: does not apply to me; not at all important; somewhat important; quite important and very important.

At follow-up, the participant is asked per selected goal to what extent the hospitalisation helped to achieve that goal. The answer options are: not at all; somewhat; quite; completely.

With the scores of the baseline and follow-up questionnaire, a Patient Benefit Index (PBI) can be calculated: this is the mean of the benefits, weighted by the importance of the goals:

$$
P B I=\sum_{i=1}^{k} \frac{G_{i}}{\sum_{i=1}^{k} G_{i}} B_{i}
$$

with $\mathrm{k}$ goal-items $\left(G_{i}\right)$ (range $0-3$, related to answer options for importance) and benefit-items $B_{i}$ (range $0-3$, related to answer options for achievement of goals).

\section{Other questionnaires and constructs}

For the construct validity the used questionnaires or constructs are summarised in Table 1. Full details are given in Additional file 1.

\section{Reliability}

Test-retest reliability of the baseline questionnaire was performed with an interval of 1 to 3 days, while the participant was still hospitalised. The participant was not notified in advance of the retest, but asked for permission for another test on the other day. Then only the PBAS HOP was repeated.

For a better understanding of the difference between test and retest, a short qualitative evaluation was done: a selection of seven participants were asked, after the retest, to explain what caused the discrepancies per item between test and retest.

Test-retest of the follow-up questionnaire was performed in another sample than the baseline test-retest with an interval of 7 to 14 days. At the end of the first follow-up interview, the participant was asked permission to be called back a week later to repeat some questions, without specifying which questions. Only the PBAS HOP was repeated.

Percentage of agreement, Cohen's Kappa with quadratic weighting and maximum attainable kappa $[11,12]$ were calculated per item for the agreement on importance of the goals on baseline, and the extent the hospitalisation helped to achieve the set goals on follow-up. Both the goal items 'doesn't apply to me' and 'not at all important' were valued as zero. For all kappa calculations an online calculator was used [13]. For the 
Table 1 Constructs measured for the construct validity

\begin{tabular}{|c|c|}
\hline Construct & Operationalisation \\
\hline Appetite & Dutch VMS screening program (VMS) [5] \\
\hline Symptoms experienced on admission day & Rotterdam Symptom Checklist (RSCL) [6] \\
\hline Pain, experienced at moment of interview & $\begin{array}{l}\text { Numeric rating scale (NRS) pain (0: no pain at all to 10: the worst } \\
\text { imaginable pain) }\end{array}$ \\
\hline Fatigue, experienced at moment of interview & NRS fatigue (0: no fatigue at all to 10: the worst imaginable fatigue) \\
\hline $\begin{array}{l}\text { Health related quality of life } 2 \text { weeks before admission/ at moment of } \\
\text { follow-up interview }\end{array}$ & EQ-5D [7] \\
\hline Admission reason & Acute/ elective; diagnostic/ curative/ palliative \\
\hline $\begin{array}{l}\text { Activities of daily living } 2 \text { weeks before admission/ at moment of follow-up } \\
\text { interview }\end{array}$ & KATZ-15 scale [8] \\
\hline Social functioning & $\begin{array}{l}\text { The Maastricht Social Participation Profile (MSPP) [9]; } \\
\text { Or 36-Item Short Form Survey Instrument (SF-36) - Social functioning } \\
\text { [10] }\end{array}$ \\
\hline Goals on hospital admission & $\begin{array}{l}\text { Open question: What do you hope to accomplish with this } \\
\text { hospitalisation? }\end{array}$ \\
\hline
\end{tabular}

interpretation of the kappa values, the classification of Landis and Koch [14] was used.

The PBI was calculated for both test and retest of baseline and follow-up and compared with Intraclass Correlation Coefficient (ICC).

\section{Validity}

\section{Baseline questionnaire}

The hypotheses we developed to test the construct validity of the baseline questionnaire are listed in Table 2.

Hypotheses 1 to 5 were evaluated using Cramér's V statistic. Hypotheses 6 and 7 were evaluated with the Spearman's rank-order correlation. Since experiencing a symptom or restraint in a certain subject, does not necessarily mean that this goal is a priority for hospital admission, the hypotheses are confirmed if the correlation exceeds 'small' as defined by Cohen [15], meaning the correlation $>0.10$. The answer option 'does not apply to me now' and 'not at all important' were coded as 0 , the options somewhat important, quite important and very important were coded respectively as 1, 2, 3. Only when the assumptions of Cramér's $\mathrm{V}$ statistic were not met because of too low (expected) cell frequency, categories were combined.

For hypothesis 8, a random selection of 50 cases was made and goals mentioned in the open question were coded using the item names of the P-BAS HOP. When a participant mentioned a goal that was not in the P-BAS

Table 2 Hypotheses baseline validity with expected and calculated correlations

\begin{tabular}{|c|c|c|c|c|c|}
\hline & \multirow[t]{2}{*}{ Hypothesis } & \multirow[t]{2}{*}{$\begin{array}{l}\text { Expected } \\
\text { correlation }\end{array}$} & \multicolumn{2}{|c|}{$\begin{array}{l}\text { Calculated } \\
\text { correlation }\end{array}$} & \multirow{2}{*}{$\begin{array}{l}\text { Confirmed } \\
\text { (C)/ } \\
\text { Rejected } \\
(\mathrm{R})\end{array}$} \\
\hline & & & $n$ & & \\
\hline 1 & $\begin{array}{l}\text { Participants who indicated a lack of appetite on the VMS and/or the RSCL, are expected to have } \\
\text { a higher priority for the goal 'appetite'. }\end{array}$ & Cramér's V > 0.10 & 450 & 0.50 & C \\
\hline 2 & $\begin{array}{l}\text { Participants who indicated tiredness and/or lack of energy on the RSCL, are expected to have a } \\
\text { higher priority for the goal 'energy'. }\end{array}$ & Cramér's V > 0.10 & 442 & 0.34 & C \\
\hline 3 & $\begin{array}{l}\text { Participants who indicated diarrhoea and/or constipation on the RSCL, are expected to have a } \\
\text { higher priority for the goal 'bowel movements'. }\end{array}$ & Cramér's V > 0.10 & 441 & 0.40 & C \\
\hline 4 & $\begin{array}{l}\text { Participants who indicated shortness of breath on the RSCL, are expected to have a higher } \\
\text { priority for the goal 'reducing shortness of breath'. }\end{array}$ & Cramér's V > 0.10 & 440 & 0.60 & C \\
\hline 5 & $\begin{array}{l}\text { Participants who had an acute admission and/or a diagnostic admission reason, are expected to } \\
\text { have a higher priority for the goal 'wanting to know what is wrong'. }\end{array}$ & Cramér's V > 0.10 & 431 & 0.25 & C \\
\hline 6 & Participants with a higher NRS pain are expected to have a higher priority for the goal 'pain'. & Spearman's $>0.10$ & 442 & 0.39 & C \\
\hline 7 & $\begin{array}{l}\text { Participants with a higher score on the SF36-social functioning, are expected to have a higher } \\
\text { priority for the goal 'visiting family or friends'. }\end{array}$ & Spearman's > 0.10 & 220 & 0.15 & C \\
\hline 8 & $\begin{array}{l}\text { Goals that were mentioned after the open question, are, when applicable, indicated as } \\
\text { minimum 'somewhat important' for the concerning goal. }\end{array}$ & $\begin{array}{l}\text { Percentage of } \\
\text { agreement } \geq 75 \%\end{array}$ & 50 & $75 \%$ & C \\
\hline
\end{tabular}


HOP, it was coded as 'other'. The coding was done by two researchers independently and then compared and discrepancies were solved by consensus. Subsequently, the percentage of agreement between the labels and the answers given in the P-BAS HOP was calculated.

The baseline questionnaire was considered valid if a minimum of $75 \%$, thus six, of the first seven hypotheses were confirmed and hypothesis 8 was confirmed in a minimum of $75 \%$ of the selected cases [16].

\section{Follow-up questionnaire}

The extent to which the hospitalisation helped to achieve the set goals is compared with the progression or deterioration of items between baseline and follow-up from other known questionnaires. Hence the formulated hypotheses are listed in Table 3.:

Hypotheses 1 to 9 were evaluated using Cramér's V statistic. Hypotheses 10 to 12 were evaluated with the Spearman's rank-order correlation. Since experiencing a progression or deterioration in a certain subject, does not necessarily mean that this is due to the hospital admission, the hypotheses are confirmed if the correlation exceeds 'small' as defined by Cohen [15], meaning the correlation $>0.10$.

For hypothesis 13 the same records were used as for hypothesis 8 on baseline. For the dyads with agreement between the code for the open question and the P-BAS HOP item, the Spearman's rank-order correlation between the answer on the open question and the corresponding P-BAS HOP item was calculated. The hypothesis was confirmed if the correlation $>0.50$.

The follow-up questionnaire was considered valid if a minimum of $75 \%$ [16], thus nine of the first 12 hypotheses, were confirmed and hypothesis 13 was confirmed.

\section{Responsiveness}

The following anchor question was used to validate the PBI: 'How much have you benefited from the admission?' With the following answer options: not at all, a little bit, somewhat, much, very much.

Table 3 Hypotheses follow-up validity with expected and calculated correlations

\begin{tabular}{|c|c|c|c|c|c|}
\hline & \multirow[t]{2}{*}{ Hypothesis } & \multirow[t]{2}{*}{$\begin{array}{l}\text { Expected } \\
\text { correlation }\end{array}$} & \multicolumn{2}{|c|}{$\begin{array}{l}\text { Calculated } \\
\text { correlation }\end{array}$} & \multirow{2}{*}{$\begin{array}{l}\text { Confirmed } \\
\text { (C)/ } \\
\text { Rejected } \\
\text { (R) }\end{array}$} \\
\hline & & & $n$ & & \\
\hline 1 & $\begin{array}{l}\text { Participants who indicated a deterioration on the Katz-15 items bathing and/or getting dressed and/ or } \\
\text { the EQ-5D item self-care, are expected to have a lower score on the item 'wash and dress yourself'. }\end{array}$ & $\begin{array}{l}\text { Cramér's V> } \\
0.10\end{array}$ & 33 & $\mathrm{nc}$ & n.a. \\
\hline 2 & $\begin{array}{l}\text { Participants who indicated a deterioration on the Katz-15 item walking and/or the EQ-5D item mobil- } \\
\text { ity, are expected to have a lower score on the item 'walking'. }\end{array}$ & $\begin{array}{l}\text { Cramér's V> } \\
0.10\end{array}$ & 116 & $0.23^{\mathrm{a}}$ & $\mathrm{R}$ \\
\hline 3 & $\begin{array}{l}\text { Participants who indicated a deterioration on the Katz-15 item travelling, are expected to have a } \\
\text { lower score on the item 'driving'. }\end{array}$ & $\begin{array}{l}\text { Cramér's V> } \\
0.10\end{array}$ & 37 & $\mathrm{nc}$ & n.a. \\
\hline 4 & $\begin{array}{l}\text { Participants who indicated a deterioration on the Katz-15 item shopping, are expected to have a } \\
\text { lower score on the item 'groceries'. }\end{array}$ & $\begin{array}{l}\text { Cramér's V> } \\
0.10\end{array}$ & 37 & $\mathrm{nc}$ & n.a. \\
\hline 5 & $\begin{array}{l}\text { Participants who indicated a deterioration on the EQ-5D item pain/discomfort, are expected to have } \\
\text { a lower score on the item 'pain'. }\end{array}$ & $\begin{array}{l}\text { Cramér's V> } \\
0.10\end{array}$ & 102 & $0.14^{\mathrm{a}}$ & $\mathrm{R}$ \\
\hline 6 & $\begin{array}{l}\text { Participants who indicated a lack of appetite on the VMS, are expected to have a lower score on the } \\
\text { item 'appetite'. }\end{array}$ & $\begin{array}{l}\text { Cramér's V> } \\
0.10\end{array}$ & 45 & 0.46 & C \\
\hline 7 & $\begin{array}{l}\text { Participants who indicated a deterioration on the MSPP item organised sports and/or the MSPP item } \\
\text { 'done something with others that required considerable physical effort', are expected to have a lower } \\
\text { score on the item 'sports'. }\end{array}$ & $\begin{array}{l}\text { Cramér's V> } \\
0.10\end{array}$ & 21 & $\mathrm{nc}$ & n.a. \\
\hline 8 & $\begin{array}{l}\text { Participants who indicated a deterioration on the MSPP item seeing family/acquaintances or the } \\
\text { SF36-social functioning, are expected to have a lower score on the item 'visiting family or friends'. }\end{array}$ & $\begin{array}{l}\text { Cramér's V> } \\
0.10\end{array}$ & 30 & $\mathrm{nc}$ & n.a. \\
\hline 9 & $\begin{array}{l}\text { Participants who moved from independent living to sheltered living or a nursing home, are expected } \\
\text { to score lower on the item 'return back to my home'. }\end{array}$ & $\begin{array}{l}\text { Cramér's V> } \\
0.10\end{array}$ & 11 & $\mathrm{nc}$ & n.a. \\
\hline 10 & $\begin{array}{l}\text { Participants with an increasing difference score between baseline and follow-up on the EQ-5D therm- } \\
\text { ometer 'general health', are expected to have a higher score on the item 'feeling better'. }\end{array}$ & $\begin{array}{l}\text { Spearman's > } \\
0.10\end{array}$ & 241 & 0.14 & C \\
\hline 11 & $\begin{array}{l}\text { Participants with an increasing difference score between baseline and follow-up on the sum score } \\
\text { 'MSPP-daytrip', are expected to have a higher score on the item 'go on outings'. }\end{array}$ & $\begin{array}{l}\text { Spearman's > } \\
0.10\end{array}$ & 33 & 0.27 & C \\
\hline 12 & $\begin{array}{l}\text { Participants with an increasing difference score between baseline and follow-up on the NRS fatigue, } \\
\text { are expected to have a lower score on the item energy. }\end{array}$ & $\begin{array}{l}\text { Spearman's }< \\
-0.10\end{array}$ & 189 & -0.14 & C \\
\hline 13 & $\begin{array}{l}\text { Accomplishing goals noted on the open question correlate with the score on the P-BAS HOP, if } \\
\text { applicable. }\end{array}$ & $\begin{array}{l}\text { Spearman's > } \\
0.50\end{array}$ & 40 & 0.71 & C \\
\hline
\end{tabular}

a association is opposite of the hypothesis; $\mathrm{nc}=$ not calculated; $\mathrm{n} . \mathrm{a} .=$ not applicable 
The PBI is considered valid when it has a Spearman's correlation coefficient $\geq 0.50$ with the anchor question $[17,18]$.

\section{Interpretability}

The interpretability is evaluated with the visual anchorbased minimal important change distribution method $[11,18]$. Participants who indicated: 'not at all', and 'a little bit', were considered as having no important benefit. Participants who indicated 'very' or 'very much', are considered as having important benefit. As it was not clear whether 'somewhat benefit' was considered as important benefit or not, we labelled this as 'borderline'. The receiver operating characteristic (ROC) curve was used to determine the optimal cut-off points for important and no important benefit.

\section{Missing values}

When the P-BAS HOP was not administered, the case was completely deleted. For all other missing values, we used pairwise deletion. The computation of the PBI was based on non-missing items.

\section{Results}

\section{Sample}

From the 2798 eligible patients, 1130 were approached for informed consent and 472 gave informed consent. After exclusion of 21 cases, we had 451 baseline cases. We lost 98 cases to follow-up and in an additional nine cases the P-BAS HOP was not administered at followup, which resulted in 344 follow-up cases. Full details are shown in Fig. 1. Most (43\%) baseline interviews were done on the third day of admission.

Sample characteristics are shown in Table 4 and Additional File 2 shows the scores of the other questionnaires measured for the construct validity.

\section{Descriptive statistics P-BAS HOP}

Table 5 shows the baseline and follow-up descriptive statistics of the P-BAS HOP. The number of goals selected as minimum 'somewhat important' varied from zero to 17 per person, with a median of five. Eleven persons selected no goals from the P-BAS HOP. Nineteen participants mentioned an extra goal. Examples of an extra goal were: resuming work; giving informal care to a relative or partner; being able to swallow. The missing values at baseline are mostly due to the interviewer accidentally omitting a question; five times it was because the participant did not know the answer.

At follow-up, participants sometimes mentioned that the goal was not applicable for them. This ranged from 1.6 to $34.0 \%$ per goal, except for the extra goal. Missing values are in two cases due to the participant stopping answering questions halfway through the P-BAS HOP.
The item 'alive' had the highest number of missing values, mostly (eight times) because the participant did not know the answer. The item 'disease under control' had the second highest number of missing values. Regarding this question, some participants mentioned they did not know how their situation was at that moment, because they were still under treatment or waiting test results.

The PBI ranged from 0 to 3 points, with a mean of 1.71 and a standard deviation of 0.93 .

\section{Reliability \\ Baseline questionnaire}

For the test-retest reliability, 60 participants were approached. Seven times the participant refused the retest, resulting in 53 participants performing a baseline test-retest reliability. Median time between test and retest was 1 day. In 33 cases the retest was performed by another interviewer and in 20 cases with the same interviewer. We therefore decided also to distinguish between intra- and inter-rater reliability.

Of the 21 specified goals, from which participants could select, the number of discrepancies between test and retest per participant ranged from zero to a maximum of 11 (52\% of the number of goals) with a median of four goals (19\%). From the cases with the same interviewer, the number of discrepancies between test and retest per participant ranged from zero to seven (33\%) with a median of three goals (14\%). The cases with different interviewers had one (5\%) to 11 (52\%) discrepancies between test and retest per participant with a median of five goals (24\%). Of the total of 228 discrepancies, in $100(44 \%)$ cases the goal was selected only during the test and in 128 (56\%) cases only during the retest. These proportions were the same for the intra- and inter-rater reliability.

The complete crosstabulations of all items are included in Additional File 3. Table 6 shows the weighted kappa per item in descending order. The weighted kappa for the item 'home' could not be calculated because of too many empty cells. Two items had substantial agreement, eight moderate agreement, seven fair agreement and three slight agreement.

When the weighted kappa was calculated as a proportion of the maximum attainable kappa, the item 'gardening' had almost perfect agreement, three items had substantial agreement, seven items moderate agreement, eight fair agreement and the item 'driving' slight agreement.

Three participants who had a retest only mentioned an extra goal in the test, while three others only mentioned an extra goal in the retest. One participant mentioned a goal in the test and in the retest, but this was a different goal. Therefore, no kappa value was calculated for the extra option. 


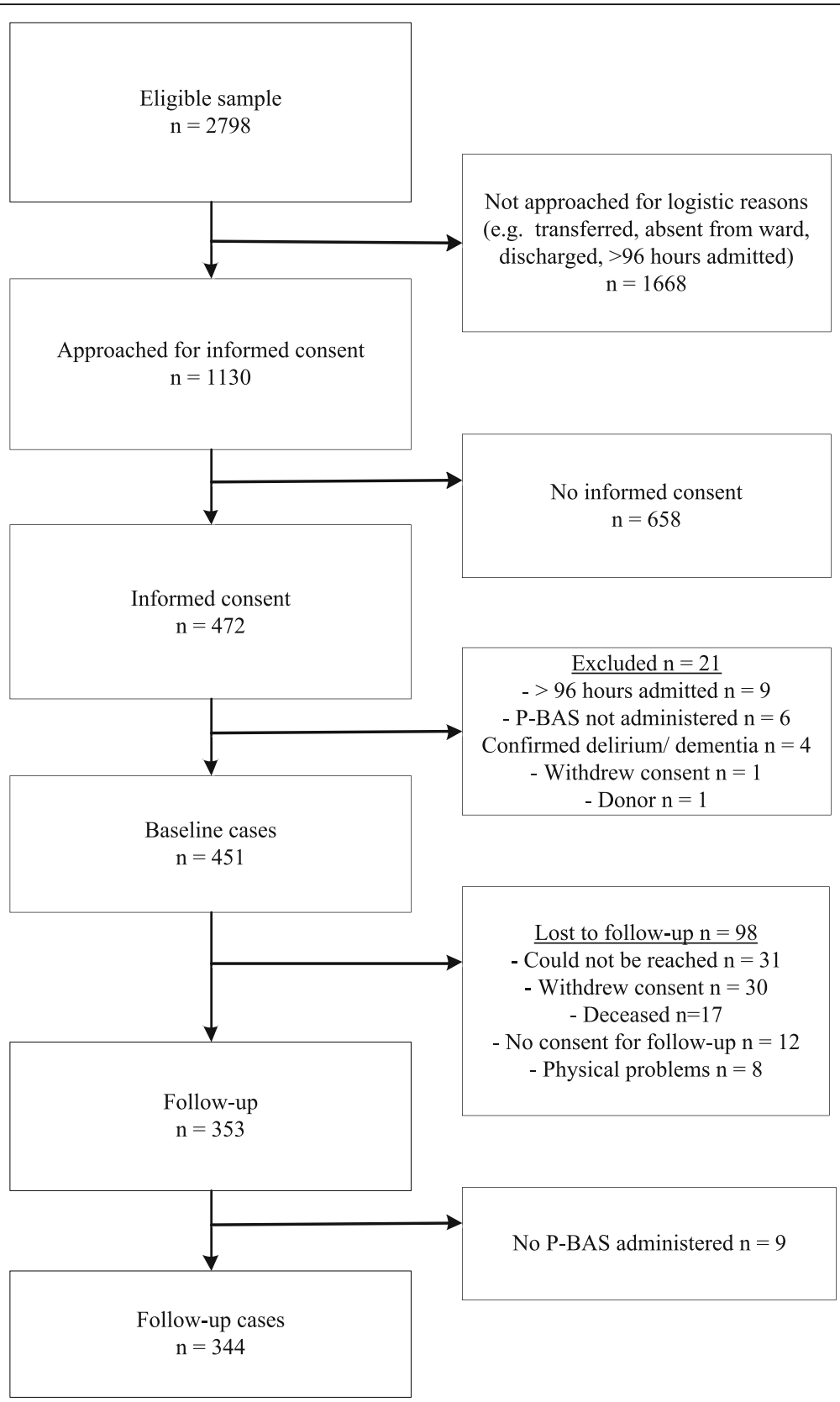

Fig. 1 Flowchart participant inclusion

The mean of all the weighted kappa values showed fair agreement, when calculated as a proportion of the maximum attainable kappa, moderate agreement. The mean of the intra-rater kappa values showed moderate agreement, when calculated as a proportion of the maximum attainable kappa, substantial agreement. The mean of the inter-rater kappa values showed fair agreement.

From the participants with a baseline retest, 37 had a valid follow-up. The PBI of the retest ranged from 0 to
3 , with a mean of 1.65 . The overall ICC between the PBI of the test and retest was 0.77 (95\% CI $0.60-0.87)$. The intra-rater ICC was $0.94(95 \%$ CI $0.81-0.98)(n=13)$, the inter-rater ICC was $0.68(95 \%$ CI $0.40-0.86)(n=24)$.

Asking the participants the reason for the discrepancies between test and retest, revealed several reasons: 1) Difference in interpretation at different moments, for example the participant had difficulties with walking due to shortness of breath, but did not have any problems 
Table 4 Sample characteristics $(n=451)$

\begin{tabular}{|c|c|}
\hline Characteristic & n (\%) \\
\hline \multicolumn{2}{|l|}{ Gender } \\
\hline Male & $300(67)$ \\
\hline Female & $151(34)$ \\
\hline Age (years), median (range) & $76(70-96)$ \\
\hline \multicolumn{2}{|l|}{ Living situation } \\
\hline Independent & $432(96)$ \\
\hline Sheltered accommodation & $14(3)$ \\
\hline Senior home & $3(1)$ \\
\hline Nursing home & $2(0)$ \\
\hline \multicolumn{2}{|l|}{ Educational level ${ }^{a}$} \\
\hline Low & $127(28)$ \\
\hline Middle & $197(44)$ \\
\hline High & $124(28)$ \\
\hline Unknown & $3(1)$ \\
\hline \multicolumn{2}{|l|}{ Specialty } \\
\hline Medical & $191(42)$ \\
\hline Surgical & $109(24)$ \\
\hline Intervention cardiology & $136(30)$ \\
\hline Unknown & $15(3)$ \\
\hline \multicolumn{2}{|l|}{ Admission type } \\
\hline Acute & $257(57)$ \\
\hline Elective & $179(40)$ \\
\hline Unknown & $15(3)$ \\
\hline Admission time (days) median (range) & $5(1-39)$ \\
\hline \multicolumn{2}{|c|}{ Interview took place after number of days after admission (days) } \\
\hline 1 & $8(2)$ \\
\hline 2 & $101(22)$ \\
\hline 3 & $193(43)$ \\
\hline 4 & $149(33)$ \\
\hline
\end{tabular}

${ }^{a}$ Educational level: Low $=$ no education, primary school, prevocational education; Middle = secondary or vocational education;

High $=$ bachelor, master

with the legs. At the retest the participant did take into account the shortness of breath, at the test only the legs. 2) Priority is assessed differently at different moments, for example groceries are normally done by the partner, but it would be nice if the participant could help, or the pain is present but the participant could cope with it. 3) Progressive insight during the hospital admission: through more information, or the experience of a disappointing recovery, goals were lowered or suddenly became much more important. 4) In some cases the participant was not able to explain the reason.

\section{Follow-up questionnaire}

For the follow-up test-retest reliability, 90 participants were approached. In 11 cases the participant refused the retest, six times the participant could not be reached, for one case it was unknown why the retest was not performed. Finally, 72 participants performed a test-retest of the follow-up questionnaire. However, since only goals that were applicable were evaluated and the prevalence of some goals was quite rare, these goals had very small sample sizes. We therefore decided to compute weighted kappa values only when the sample size was $\geq 10$ participants. Median time between test and retest was 9.5 days. In 43 cases the retest was performed by another interviewer and in 29 cases by the same interviewer. Sample sizes were too small to calculate kappa values for intra- and inter-rater reliability. Six values can be found in Additional file 4 .

The complete crosstabulations of all the items are included in Additional File 4. Table 7 shows the weighted kappa in descending order. The item 'enjoying life' had almost perfect agreement. Two items had substantial agreement, six moderate agreement, two fair agreement and the item 'knowing what is wrong' slight agreement.

When the weighted kappa was calculated as a proportion of the maximum attainable kappa, four items had almost perfect agreement, three substantial agreement, three moderate agreement, one fair agreement and one slight agreement.

For ten items the sample size was too small to calculate a valid kappa. The percentage of agreement for these items varied widely from zero for groceries to one hundred for home and the extra goal, although these last two items were only answered by one and two participants, respectively.

The mean of all the weighted kappa values showed a moderate agreement, when calculated as a proportion of the maximum attainable kappa, a substantial agreement.

The PBI of the retest ranged from 0 to 3 points, with a mean of 1.77. The overall ICC between the PBI of the test and retest was $0.62(96 \% \mathrm{CI} 0.45-0.74)$. The intrarater ICC was 0.59 (95\% CI 0.29-0.78), the inter-rater ICC was 0.64 (95\% CI 0.42-0.79).

\section{Validity \\ Baseline questionnaire}

All baseline hypotheses were confirmed. Table 2 shows the test statistics and the complete descriptive information is shown in Additional file 5.

The 50 cases selected for the open question mentioned 110 goals in total. Of these, 23 goals could not be coded as an item in the P-BAS HOP because they were too vague to categorise or the goal did not exist in the PBAS HOP and were therefore coded as 'other'. An example of a vague goal was: 'that it will be the way it was', an example of a goal that did not exist in the P-BAS HOP was: 'that I can lift my grandson again'. We consequently analysed the agreement between the codes and 
Table 5 P-BAS HOP Baseline and follow-up descriptive statistics

\begin{tabular}{|c|c|c|c|c|c|c|c|c|c|c|c|c|}
\hline \multirow[t]{3}{*}{ Item } & \multicolumn{6}{|l|}{ Baseline } & \multicolumn{6}{|l|}{ Follow-up } \\
\hline & \multirow[b]{2}{*}{$\begin{array}{l}\text { Not applicable } \\
\text { for me } \\
\mathrm{n}(\%)\end{array}$} & \multicolumn{4}{|c|}{ Importance } & \multirow[b]{2}{*}{$\begin{array}{l}\text { Mis } \\
\text { sing } \\
(\%)\end{array}$} & \multirow[b]{2}{*}{$\begin{array}{l}\text { Not applicable } \\
\text { for me } \\
\mathrm{n}(\%)\end{array}$} & \multicolumn{4}{|c|}{ Achievement } & \multirow[b]{2}{*}{ Missing } \\
\hline & & $\begin{array}{l}\text { Not at } \\
\text { all } \\
\mathrm{n}(\%)\end{array}$ & $\begin{array}{l}\text { Some- } \\
\text { what } \\
\text { n (\%) }\end{array}$ & $\begin{array}{l}\text { Quite } \\
\text { n (\%) }\end{array}$ & $\begin{array}{l}\text { Very } \\
\mathrm{n}(\%)\end{array}$ & & & $\begin{array}{l}\text { Not at } \\
\text { all } \\
n(\%)\end{array}$ & $\begin{array}{l}\text { Some- } \\
\text { what } \\
\text { n (\%) }\end{array}$ & $\begin{array}{l}\text { Quite } \\
\text { n (\%) }\end{array}$ & $\begin{array}{l}\text { Completely } \\
\text { n (\%) }\end{array}$ & \\
\hline Better & $116(25.7)$ & $2(0.4)$ & $8(1.8)$ & $\begin{array}{l}64 \\
(14.2)\end{array}$ & $\begin{array}{l}259 \\
(57.4)\end{array}$ & $2(0.4)$ & $4(1.6)$ & $\begin{array}{l}40 \\
(15.6)\end{array}$ & $59(23.0)$ & $\begin{array}{l}74 \\
(28.8)\end{array}$ & $77(30.0)$ & $3(1.2)$ \\
\hline Energy & $194(43.0)$ & $2(0.4)$ & $16(3.5)$ & $\begin{array}{l}77 \\
(17.1)\end{array}$ & $\begin{array}{l}161 \\
(35.7)\end{array}$ & $1(0.2)$ & $8(4.0)$ & $\begin{array}{l}68 \\
(33.8)\end{array}$ & $45(22.4)$ & $\begin{array}{l}50 \\
(24.9)\end{array}$ & $27(13.4)$ & $3(1.5)$ \\
\hline Pain & $293(65.0)$ & $1(0.2)$ & $12(2.7)$ & $\begin{array}{l}40 \\
(8.9)\end{array}$ & $\begin{array}{l}105 \\
(23.3)\end{array}$ & 0 & $17(14.2)$ & $\begin{array}{l}28 \\
(23.3)\end{array}$ & $18(15.0)$ & $\begin{array}{l}20 \\
(16.7)\end{array}$ & 37 (30.8) & 0 \\
\hline $\begin{array}{l}\text { Bowel } \\
\text { movements }\end{array}$ & $381(84.5)$ & $1(0.2)$ & $5(1.1)$ & $\begin{array}{l}21 \\
(4.7)\end{array}$ & $\begin{array}{l}41 \\
(9.1)\end{array}$ & $2(0.4)$ & $10(19.2)$ & $\begin{array}{l}11 \\
(21.2)\end{array}$ & $3(5.8)$ & $\begin{array}{l}8 \\
(15.4)\end{array}$ & $17(32.7)$ & $3^{\mathrm{a}}(5.8)$ \\
\hline $\begin{array}{l}\text { Shortness of } \\
\text { breath }\end{array}$ & $272(60.3)$ & $1(0.2)$ & $14(3.1)$ & $\begin{array}{l}44 \\
(9.8)\end{array}$ & $\begin{array}{l}118 \\
(26.2)\end{array}$ & $2(0.4)$ & $8(6.1)$ & $\begin{array}{l}41 \\
(31.3)\end{array}$ & $27(20.6)$ & $\begin{array}{l}26 \\
(19.8)\end{array}$ & $26(19.8)$ & $3(2.3)$ \\
\hline Walking & $292(64.7)$ & $1(0.2)$ & $8(1.8)$ & $\begin{array}{l}36 \\
(8.0)\end{array}$ & $\begin{array}{l}109 \\
(24.2)\end{array}$ & $5(1.1)$ & $6(4.8)$ & $\begin{array}{l}47 \\
(37.3)\end{array}$ & $22(17.5)$ & $\begin{array}{l}22 \\
(17.5)\end{array}$ & $24(19.0)$ & $5^{a}(4.0)$ \\
\hline Appetite & $389(86.3)$ & $1(0.2)$ & $9(2.0)$ & $\begin{array}{l}20 \\
(4.4)\end{array}$ & $\begin{array}{l}32 \\
(7.1)\end{array}$ & 0 & $6(12.5)$ & $\begin{array}{l}14 \\
(29.2)\end{array}$ & $7(14.6)$ & $\begin{array}{l}6 \\
(12.5)\end{array}$ & 15 (31.3) & 0 \\
\hline $\begin{array}{l}\text { Knowing what is } \\
\text { wrong }\end{array}$ & $337(74.7)$ & 0 & $8(1.8)$ & $\begin{array}{l}20 \\
(4.4)\end{array}$ & $\begin{array}{l}81 \\
(18.0)\end{array}$ & $5(1.1)$ & $6(7.1)$ & $8(9.4)$ & $6(7.1)$ & $\begin{array}{l}10 \\
(11.8)\end{array}$ & $54(63.5)$ & $1(1.2)$ \\
\hline $\begin{array}{l}\text { Disease under } \\
\text { control }\end{array}$ & $216(47.9)$ & $1(0.2)$ & $5(1.1)$ & $\begin{array}{l}39 \\
(8.6)\end{array}$ & $\begin{array}{l}188 \\
(41.7)\end{array}$ & $2(0.4)$ & $3(1.6)$ & $\begin{array}{l}39 \\
(20.6)\end{array}$ & $36(19.0)$ & $\begin{array}{l}32 \\
(16.9)\end{array}$ & $72(38.1)$ & $7(3.7)$ \\
\hline Alive & $243(53.9)$ & 0 & $3(0.7)$ & $\begin{array}{l}20 \\
(4.4)\end{array}$ & $\begin{array}{l}183 \\
(40.6)\end{array}$ & $2(0.4)$ & $7(4.3)$ & $\begin{array}{l}10 \\
(6.2)\end{array}$ & $14(8.7)$ & $\begin{array}{l}15 \\
(9.3)\end{array}$ & $103(64.0)$ & $12(2.7)$ \\
\hline Enjoy & $304(67.4)$ & 0 & $3(0.7)$ & $\begin{array}{l}45 \\
(10.0)\end{array}$ & $\begin{array}{l}96 \\
(21.3)\end{array}$ & $3(0.7)$ & $13(11.4)$ & $\begin{array}{l}18 \\
(15.8)\end{array}$ & 25 (21.9) & $\begin{array}{l}24 \\
(21.1)\end{array}$ & $30(26.3)$ & $4(3.5)$ \\
\hline Groceries & $386(85.6)$ & $2(0.4)$ & $7(1.6)$ & $\begin{array}{l}20 \\
(4.4)\end{array}$ & $\begin{array}{l}36 \\
(8.0)\end{array}$ & 0 & $14(26.9)$ & $\begin{array}{l}13 \\
(25.0)\end{array}$ & $4(7.7)$ & $\begin{array}{l}6 \\
(11.5)\end{array}$ & $14(26.9)$ & $1(1.9)$ \\
\hline Wash and dress & $384(85.1)$ & 0 & $3(0.7)$ & $\begin{array}{l}19 \\
(4.2)\end{array}$ & $\begin{array}{l}43 \\
(9.5)\end{array}$ & $2(0.4)$ & $18(34.0)$ & $\begin{array}{l}10 \\
(18.9)\end{array}$ & $4(7.5)$ & $\begin{array}{l}3 \\
(5.7)\end{array}$ & $16(20.2)$ & $2(3.8)$ \\
\hline Garden & $365(80.9)$ & $4(0.9)$ & $14(3.1)$ & $\begin{array}{l}21 \\
(4.7)\end{array}$ & $\begin{array}{l}46 \\
(10.2)\end{array}$ & $1(0.2)$ & $10(14.5)$ & $\begin{array}{l}18 \\
(26.1)\end{array}$ & $16(23.2)$ & $\begin{array}{l}11 \\
(15.9)\end{array}$ & $14(20.3)$ & 0 \\
\hline Sports & 359 (79.6) & $4(0.9)$ & $9(2.0)$ & $\begin{array}{l}30 \\
(6.7)\end{array}$ & $\begin{array}{l}48 \\
(10.6)\end{array}$ & $1(0.2)$ & 15 (19.7) & $\begin{array}{l}26 \\
(34.2)\end{array}$ & $8(10.5)$ & $\begin{array}{l}10 \\
(13.2)\end{array}$ & $14(18.4)$ & $3(3.9)$ \\
\hline Hobbies & $374(82.9)$ & $1(0.2)$ & $8(1.8)$ & $\begin{array}{l}22 \\
(4.9)\end{array}$ & $\begin{array}{l}46 \\
(10.2)\end{array}$ & 0 & $8(12.9)$ & $\begin{array}{l}18 \\
(29.0)\end{array}$ & $9(14.5)$ & $\begin{array}{l}10 \\
(16.1)\end{array}$ & $15(24.2)$ & $2(3.2)$ \\
\hline Driving & $388(86.0)$ & $1(0.2)$ & $3(0.7)$ & $\begin{array}{l}12 \\
(2.7)\end{array}$ & $\begin{array}{l}46 \\
(10.2)\end{array}$ & $1(0.2)$ & $13(25.0)$ & $\begin{array}{l}15 \\
(28.8)\end{array}$ & $2(3.8)$ & $\begin{array}{l}2 \\
(3.8)\end{array}$ & $18(34.6)$ & $2(3.8)$ \\
\hline Outings & $369(81.8)$ & $2(0.4)$ & $7(1.6)$ & $\begin{array}{l}28 \\
(6.2)\end{array}$ & $\begin{array}{l}44 \\
(9.8)\end{array}$ & $1(0.2)$ & $9(14.5)$ & $\begin{array}{l}23 \\
(37.1)\end{array}$ & $11(17.7)$ & $\begin{array}{l}9 \\
(14.5)\end{array}$ & $8(12.9)$ & $2(3.2)$ \\
\hline Visiting & $391(86.7)$ & 0 & $5(1.1)$ & $\begin{array}{l}20 \\
(4.4)\end{array}$ & $\begin{array}{l}34 \\
(7.5)\end{array}$ & $1(0.2)$ & $11(24.4)$ & $\begin{array}{l}18 \\
(40.0)\end{array}$ & $5(11.1)$ & $\begin{array}{l}3 \\
(6.7)\end{array}$ & $8(17.8)$ & 0 \\
\hline Home & $423(93.8)$ & $1(0.2)$ & 0 & $\begin{array}{l}7 \\
(1.6)\end{array}$ & $\begin{array}{l}20 \\
(4.4)\end{array}$ & 0 & $3(18.8)$ & $1(6.3)$ & $1(6.3)$ & 0 & $10(62.5)$ & $1(6.3)$ \\
\hline Independence & 377 (83.6) & $1(0.2)$ & $1(0.2)$ & $\begin{array}{l}18 \\
(4.0)\end{array}$ & $\begin{array}{l}52 \\
(11.5)\end{array}$ & $2(0.4)$ & $11(22.4)$ & $\begin{array}{l}13 \\
(26.5)\end{array}$ & $7(14.3)$ & $\begin{array}{l}10 \\
(20.4)\end{array}$ & $7(14.3)$ & $1(2.0)$ \\
\hline Extra & $432(95.8)$ & 0 & 0 & $\begin{array}{l}2 \\
(0.4)\end{array}$ & $\begin{array}{l}17 \\
(3.8)\end{array}$ & 0 & 0 & $\begin{array}{l}5 \\
(35.7)\end{array}$ & $2(14.3)$ & $\begin{array}{l}2 \\
(14.3)\end{array}$ & $3(21.4)$ & $2(14.3)$ \\
\hline
\end{tabular}

${ }^{a}$ Due to a random temporary error in the computer system, the items defecation $(n=2)$ and walking $(n=4)$ were not asked

the answers given in the P-BAS HOP of 87 goals and found an agreement of $75 \%$. An overview of the number of items coded and the amount of agreement is given in Table 8.

\section{Follow-up questionnaire}

Six hypotheses did not meet the assumptions for Cramér's $\mathrm{V}$, because the number of people experiencing a deterioration on that item was very low. For four of 
Table 6 Cohen's weighted kappa with quadratic weighting for baseline items in descending order

\begin{tabular}{|c|c|c|c|c|c|c|c|c|c|c|c|c|}
\hline \multirow[t]{2}{*}{ Item } & \multicolumn{4}{|c|}{ Overall reliability $(n=50-53)$} & \multicolumn{4}{|c|}{ Intra-rater reliability $(n=19-20)$} & \multicolumn{4}{|c|}{ Inter-rater reliability $(n=31-33)$} \\
\hline & $\%^{\mathrm{a}}$ & $\begin{array}{l}\text { Weighted Kappa } \\
(95 \% \text { Cl) }\end{array}$ & $\mathrm{K}_{\max }$ & $\begin{array}{l}\mathrm{K} / \\
\mathrm{K}_{\max }\end{array}$ & $\%^{\mathrm{a}}$ & $\begin{array}{l}\text { Weighted Kappa } \\
(95 \% \text { Cl) }\end{array}$ & $\mathrm{K}_{\max }$ & $\begin{array}{l}\mathrm{K} / \\
\mathrm{K}_{\max }\end{array}$ & $\%^{\mathrm{a}}$ & $\begin{array}{l}\text { Weighted Kappa } \\
(95 \% \mathrm{Cl})\end{array}$ & $\mathrm{K}_{\max }$ & $\begin{array}{l}\mathrm{K} / \\
\mathrm{K}_{\max }\end{array}$ \\
\hline Bowel movement & 88.68 & $0.66(0.37 ; 0.96)$ & 0.95 & 0.70 & 95.00 & $0.85(0.51 ; 1)$ & 0.85 & 1 & 84.85 & $0.58(0.21 ; 0.95)$ & 0.86 & 0.68 \\
\hline Walking & 64.00 & $0.63(0.46 ; 0.81)$ & 0.95 & 0.61 & 78.95 & $0.84(0.72 ; 0.97)$ & 0.87 & 0.97 & 54.84 & $0.49(0.23 ; 0.75)$ & 0.84 & 0.58 \\
\hline Gardening & 84.91 & $0.55(0.26 ; 0.84)$ & 0.68 & 0.81 & 85.00 & $0.74(0.41 ; 1)$ & $\mathrm{nc}$ & $\mathrm{nc}$ & 84.85 & $0.39(0.05 ; 0.74)$ & 0.66 & 0.60 \\
\hline $\begin{array}{l}\text { Shortness of } \\
\text { breath }\end{array}$ & 60.38 & $0.54(0.33 ; 0.75)$ & 0.97 & 0.56 & 60.00 & $0.56(0.24 ; 0.88)$ & 0.97 & 0.58 & 60.61 & $0.53(0.26 ; 0.80)$ & 0.91 & 0.58 \\
\hline Independence & 80.77 & $0.54(0.28 ; 0.79)$ & 0.96 & 0.56 & 85.00 & $0.74(0.48 ; 0.99)$ & $\mathrm{nc}$ & $\mathrm{nc}$ & 78.13 & $0.44(0.11 ; 0.77)$ & 0.86 & 0.51 \\
\hline Pain & 66.04 & $0.52(0.32 ; 0.72)$ & 0.95 & 0.55 & 75.00 & $0.56(0.24 ; 0.88)$ & 0.83 & 0.67 & 60.61 & $0.49(0.24 ; 0.74)$ & 0.76 & 0.64 \\
\hline Sports & 75.47 & $0.51(0.25 ; 0.76)$ & 0.75 & 0.68 & 80.00 & $0.65(0.30 ; 0.99)$ & 0.96 & 0.67 & 72.73 & $0.38(0.10 ; 0.66)$ & nc & $\mathrm{nc}$ \\
\hline $\begin{array}{l}\text { Knowing what is } \\
\text { wrong }\end{array}$ & 67.92 & $0.48(0.26 ; 0.70)$ & 0.95 & 0.50 & 60.00 & $0.30(0 ; 0.68)$ & 0.97 & 0.31 & 72.73 & $0.58(0.33 ; 0.83)$ & 0.88 & 0.66 \\
\hline Energy & 54.72 & $0.43(0.21 ; 0.66)$ & 0.94 & 0.46 & 65.00 & $0.62(0.30 ; 0.86)$ & 0.62 & 1 & 48.48 & $0.35(0.09 ; 0.61)$ & 0.64 & 0.55 \\
\hline $\begin{array}{l}\text { Controlling } \\
\text { disease }\end{array}$ & 59.62 & $0.42(0.21 ; 0.63)$ & 0.78 & 0.54 & 60.00 & $0.50(0.20 ; 0.80)$ & 0.62 & 0.80 & 59.38 & $0.38(0.11 ; 0.66)$ & 0.95 & 0.40 \\
\hline Groceries & 77.36 & $0.40(0.14 ; 0.66)$ & 0.95 & 0.42 & 90.00 & 0.85 (nc) & 0.85 & 1 & 69.70 & $0.28(0 ; 0.57)$ & 0.94 & 0.30 \\
\hline Hobbies & 76.92 & $0.30(0.03 ; 0.57)$ & 0.95 & 0.31 & 70.00 & $0.34(0 ; 0.74)$ & 0.94 & 0.36 & 81.25 & $0.27(0 ; 0.62)$ & 0.70 & 0.38 \\
\hline Visiting & 75.47 & $0.29(0.05 ; 0.53)$ & 0.96 & 0.30 & 75.00 & $0.47(0.09 ; 0.85)$ & 0.86 & 0.55 & 75.76 & $0.14(0 ; 0.28)$ & 0.95 & 0.14 \\
\hline Outings & 67.31 & $0.28(0.09 ; 0.48)$ & 0.74 & 0.38 & 70.00 & $0.44(0.13 ; 0.74)$ & 0.44 & 1 & 65.63 & $0.21(0 ; 0.43)$ & 0.99 & 0.21 \\
\hline Alive & 62.26 & $0.28(0.06 ; 0.50)$ & 0.91 & 0.31 & 75.00 & $0.45(0.09 ; 0.80)$ & 0.72 & 0.63 & 54.55 & $0.16(0 ; 0.43)$ & 0.99 & 0.16 \\
\hline Appetite & 75.00 & $0.25(0.07 ; 0.43)$ & 0.66 & 0.38 & 73.68 & $\mathrm{nc}$ & $\mathrm{nc}$ & $\mathrm{nc}$ & 75.76 & $0.46(0 ; 0.93)$ & 0.72 & 0.65 \\
\hline $\begin{array}{l}\text { Washing and } \\
\text { dressing }\end{array}$ & 73.08 & $0.25(0.02 ; 0.48)$ & 0.96 & 0.26 & 70.00 & $0.29(0 ; 0.61)$ & 0.72 & 0.40 & 75.00 & $0.23(0 ; 0.53)$ & 0.83 & 0.28 \\
\hline Enjoying life & 65.38 & $0.17(0 ; 0.38)$ & 0.75 & 0.23 & 85.00 & $0.65(0.34 ; 0.97)$ & 0.65 & 1 & 53.13 & $-0.12(-0.39 ; 0.14)$ & 0.85 & -0.14 \\
\hline Better & 60.38 & $0.14(0.01 ; 0.27)$ & 0.60 & 0.23 & 75.00 & $0.62(0.23 ; 1)$ & 0.84 & 0.74 & 51.52 & $-0.16(n c)$ & 0.52 & -0.31 \\
\hline Driving & 83.02 & 0.05 (nc) & 0.87 & 0.05 & 95.00 & $0.44(0 ; 1)$ & 0.44 & 1 & 75.76 & -0.08 (nc) & 0.62 & -0.14 \\
\hline Home & 94.23 & $\mathrm{nc}$ & $\mathrm{nc}$ & $\mathrm{nc}$ & 95.00 & $\mathrm{nc}$ & $\mathrm{nc}$ & $\mathrm{nc}$ & 93.75 & nc & $\mathrm{nc}$ & $\mathrm{nc}$ \\
\hline Extra & $\mathrm{nc}$ & $\mathrm{nc}$ & $\mathrm{nc}$ & $\mathrm{nc}$ & $\mathrm{nc}$ & $\mathrm{nc}$ & $\mathrm{nc}$ & $\mathrm{nc}$ & $\mathrm{nc}$ & $\mathrm{nc}$ & $\mathrm{nc}$ & $\mathrm{nc}$ \\
\hline Mean & 72.04 & 0.38 & 0.86 & 0.44 & 77.03 & 0.58 & 0.77 & 0.75 & 69.00 & 0.30 & 0.81 & 0.35 \\
\hline
\end{tabular}

${ }^{\mathrm{a}} \%$ = percentage of agreement, $\mathrm{K}=$ kappa $\mathrm{K}_{\max }=$ maximum attainable weighted kappa $\mathrm{Cl}=$ Confidence interval $\mathrm{nc}=$ not calculated

these hypotheses the descriptive trend was in the right direction. From six of the first 12 hypotheses that were calculated, four were confirmed and two were rejected. Table 3 shows the test statistics and the complete descriptive information is shown in Additional File 6.

Of the 50 cases selected at baseline for comparing open questions, 41 had a follow-up. This resulted in 40 dyads of coded open goals and P-BAS HOP items with a follow-up. The correlation between the answers on the open question and the corresponding P-BAS HOP item was 0.71 .

\section{Responsiveness}

For the anchor question 'How much have you benefited from the admission?' Thirteen (4\%) of the respondents did not know what to answer. Of the valid responses, 15 (5\%) of the respondents answered 'not at all', 15 (5\%) 'a little bit', 44 (13\%) 'somewhat', 142 (43\%) much, and 113 (34\%) very much.

The Spearman's correlation coefficient between the $\mathrm{PBI}$ and the anchor question was 0.51 .

\section{Interpretability}

Figure 2 shows on the left side the ROC curve of 'no important benefit', with an area under the curve of 0.73 . The optimal cut-off point for 'no important benefit' was set at a sensitivity value of $73 \%$ and a specificity of $73 \%$, resulting in an MIC of 0.7 points on the PBI.

The right side of Fig. 2 shows the ROC curve of 'important benefit', with an area under the curve of 0.80 . The optimal cut-off point for 'important benefit' was set at a sensitivity value of $79 \%$ and a specificity of $75 \%$, resulting in a MIC of 1.4 points on the PBI. This means the PBI values between 0.7 and 1.4 are considered as 
Table 7 Cohen's weighted kappa with quadratic weighting for follow-up items in descending order $(n=1-51)$

\begin{tabular}{|c|c|c|c|c|c|}
\hline Item & $\mathrm{n}$ & $\%$ agreement & Weighted Kappa (95\% CI) & $\mathrm{K}_{\max }$ & Weighted $\mathrm{K} / \mathrm{K}_{\max }$ \\
\hline Enjoying life & 17 & 88.24 & $0.88(0.65 ; 1)$ & 0.98 & 0.91 \\
\hline Pain & 14 & 42.86 & 0.72 (nc) & 0.82 & 0.88 \\
\hline Sports & 12 & 41.67 & $0.61(0.39 ; 0.83)$ & 0.71 & 0.86 \\
\hline Controlling disease & 29 & 55.17 & $0.59(0.28 ; 0.90)$ & 0.87 & 0.67 \\
\hline Driving & 10 & 60.00 & $0.55(0.07 ; 1)$ & 0.97 & 0.56 \\
\hline Better & 51 & 50.98 & $0.51(0.20 ; 0.81)$ & 0.74 & 0.68 \\
\hline Alive & 28 & 60.71 & $0.50(0.18 ; 0.82)$ & 0.57 & 0.87 \\
\hline Shortness of breath & 25 & 56.00 & $0.47(0.07 ; 0.88)$ & 0.75 & 0.63 \\
\hline Energy & 41 & 43.90 & $0.45(0.16 ; 0.74)$ & 0.89 & 0.51 \\
\hline Gardening & 13 & 46.15 & $0.40(0 ; 87)$ & 0.74 & 0.54 \\
\hline Walking & 25 & 36.00 & $0.24(0 ; 0.50)$ & 0.83 & 0.28 \\
\hline Knowing what is wrong & 10 & 70.00 & 0.17 (nc) & 1 & 0.17 \\
\hline Bowel movement & 5 & 40.00 & $\mathrm{nc}$ & nc & $\mathrm{nc}$ \\
\hline Appetite & 9 & 77.77 & $\mathrm{nc}$ & nc & $\mathrm{nc}$ \\
\hline Groceries & 5 & 0 & $\mathrm{nc}$ & nc & $\mathrm{nc}$ \\
\hline Washing and dressing & 5 & 60.00 & $\mathrm{nc}$ & nc & $\mathrm{nc}$ \\
\hline Hobbies & 6 & 50.00 & $\mathrm{nc}$ & $\mathrm{nc}$ & nc \\
\hline Visiting & 4 & 25.00 & $\mathrm{nc}$ & $\mathrm{nc}$ & $\mathrm{nc}$ \\
\hline Outings & 7 & 57.14 & $\mathrm{nc}$ & nc & $\mathrm{nc}$ \\
\hline Home & 1 & 100 & $\mathrm{nc}$ & nc & $\mathrm{nc}$ \\
\hline Independence & 7 & 14.28 & $\mathrm{nc}$ & $\mathrm{nc}$ & $\mathrm{nc}$ \\
\hline Extra & 2 & 100 & $\mathrm{nc}$ & $\mathrm{nc}$ & $\mathrm{nc}$ \\
\hline Mean & 15 & 53.43 & 0.51 & 0.83 & 0.63 \\
\hline
\end{tabular}

Cl Confidence interval, nc not calculated

'borderline benefit'. The anchor-based MIC distribution is displayed in Fig. 3.

\section{Discussion}

In this study we tested the reliability, validity, responsiveness and interpretability of the Patient Benefit Assessment scale (P-BAS HOP), which was designed to identify the goals of the individual patient and to measure his/her relevant outcomes. The results are mixed.

The reliability of the individual items of the baseline questionnaire can be summarised as fair to moderate. Participants varied regularly in which goals they considered important. This could have several causes. Firstly, although sample sizes being small, the intra-rater reliability of the baseline test appeared to be much better than inter-rater. It could have happened that the interviewer unintentionally influenced a participant when remembering the answer from the other day, but it is more probable that there is much variation between instructions given by various interviewers. This could be caused by not having all questions written out, giving more autonomy to the interviewer, or the instructions may have been insufficient. Secondly, a hospital admission is a highly unstable and unpredictable period. Symptoms vary, people receive treatments and medical information which can change their priorities. Thirdly, the definition of a problem or limitation was perhaps not very clear, since this could have been at the moment of interview, or at the moment of admission, or could have been a potential limitation. This could cause large differences in the crosstabulations: when someone, for example, declares at the test in the first step that an item does not apply, the answer is automatically doesn't apply/not important at all, while when saying in the retest it does apply the participant goes further to the second step and can indicate there that it is 'very important'. Fourthly, choosing which goals or items are relevant, is very different from usual questionnaires where the objective is to assess, for example, health status. When comparing the P-BAS HOP with other instruments where participants choose their own domains, it is seen that choosing other domains in the retest is common. For example in the 'schedule for the evaluation of individual quality of life' (SEIQoL-DW), 35 to $81 \%$ of the 
Table 8 Coding of open questions and agreement with P-BAS HOP in descending order of frequency

\begin{tabular}{|c|c|c|c|}
\hline Code & Frequency coded & Agreement n (\%) & No agreement $\mathrm{n}(\%)$ \\
\hline Other & 23 & n.a. & n.a. \\
\hline Controlling disease & 16 & $14(88)$ & $2(13)$ \\
\hline Pain & 9 & $6(67)$ & $3(33)$ \\
\hline Shortness of breath & 8 & $8(100)$ & 0 \\
\hline Walking & 8 & $7(88)$ & $1(13)$ \\
\hline Independence & 8 & $5(63)$ & $3(38)$ \\
\hline Better & 7 & $7(100)$ & 0 \\
\hline Sports & 7 & $3(43)$ & $4(57)$ \\
\hline Alive & 6 & $4(67)$ & $2(33)$ \\
\hline Energy & 5 & $5(100)$ & 0 \\
\hline Outings & 5 & $2(40)$ & $3(60)$ \\
\hline Hobbies & 3 & $1(33)$ & $2(67)$ \\
\hline Garden & 2 & $1(50)$ & $1(50)$ \\
\hline Knowing what is wrong & 1 & $1(100)$ & 0 \\
\hline Groceries & 1 & $1(100)$ & 0 \\
\hline Driving & 1 & 0 & $1(100)$ \\
\hline Bowel movements & 0 & n.a. & n.a. \\
\hline Appetite & 0 & n.a. & n.a. \\
\hline Enjoy & 0 & n.a. & n.a. \\
\hline Wash and dress & 0 & n.a. & n.a. \\
\hline Visiting & 0 & n.a. & n.a. \\
\hline Home & 0 & n.a. & n.a. \\
\hline Total & 110 & $65(75)$ & $22(25)$ \\
\hline
\end{tabular}
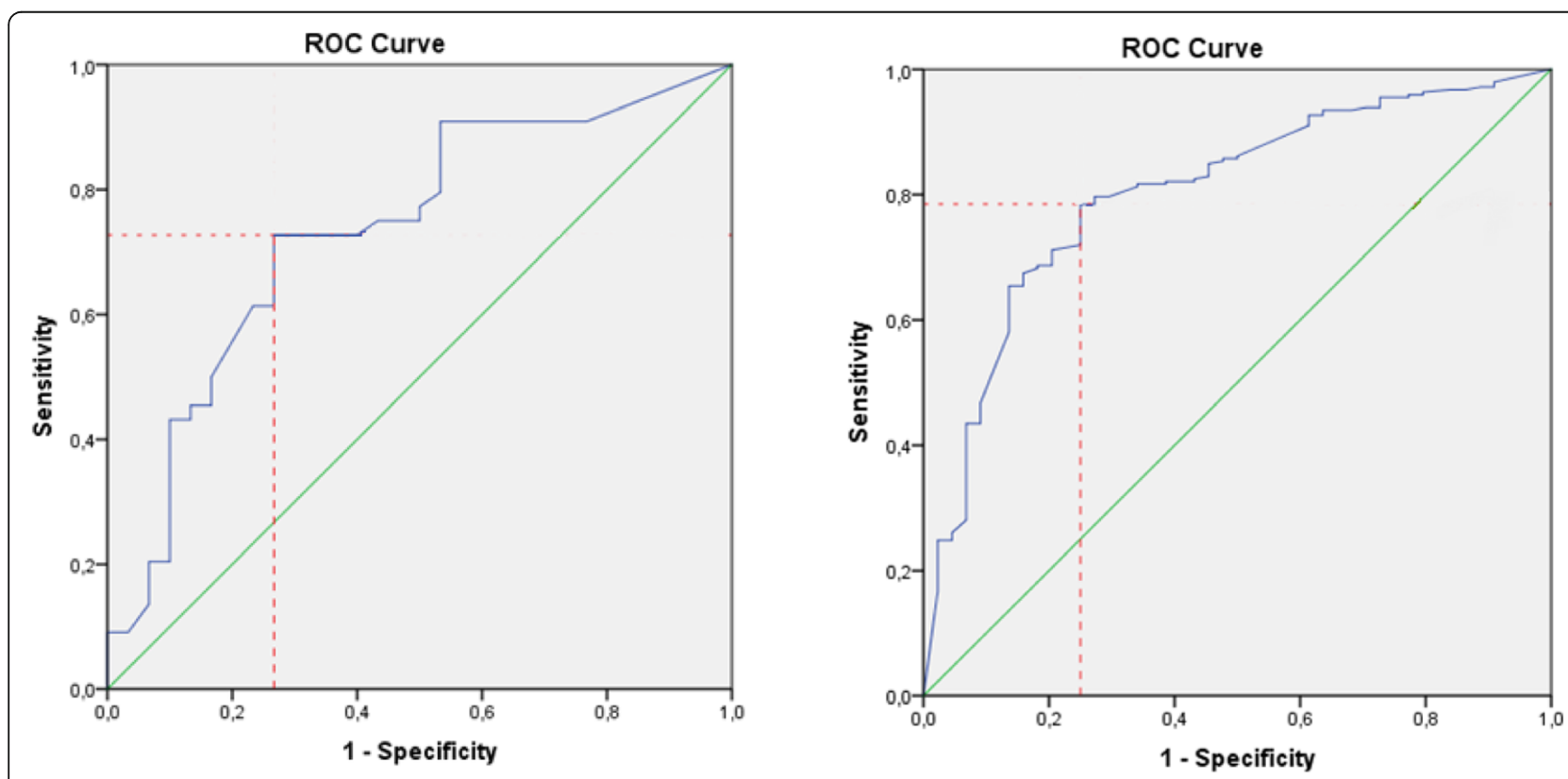

Fig. 2 ROC curve of 'no benefit' (left, $n=74$, AUC $=0.73$ ) and 'benefit' (right, $n=290$, AUC $=0.80$ ) with optimal cut-off point. ROC $=$ receiver operating characteristic, $A \cup C=$ Area under de curve 


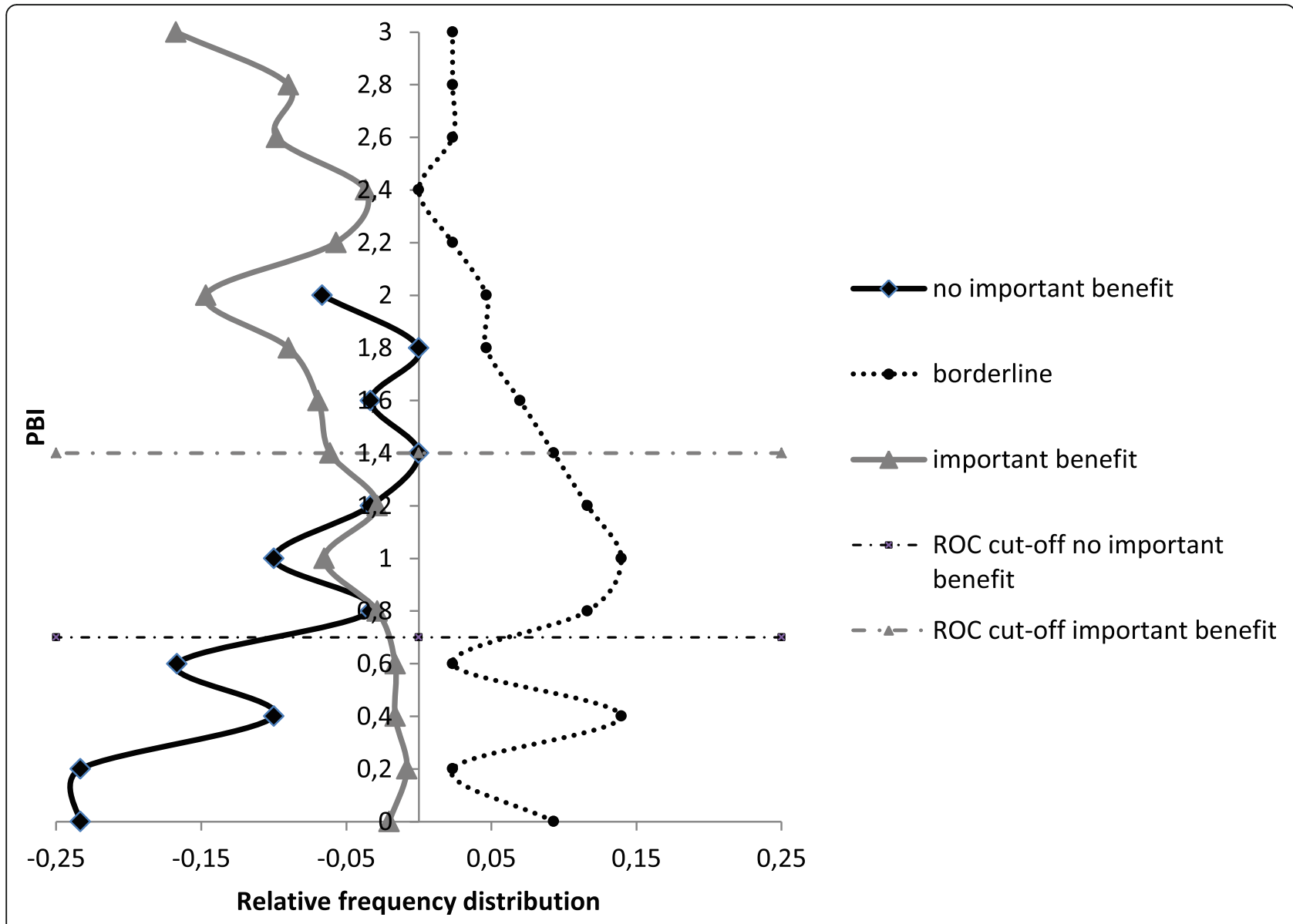

Fig. 3 Anchor-based minimal important change (MIC) distribution. PBI = Patient Benefit Index

participants choose new domains $[19,20]$. In the Patient-Generated Index (PGI) participants have to choose a maximum of five domains and the mean number of change in the retest was 1.7. $21 \%$ of the participants chose three to five new domains $[20,21]$.

A more technical explanation for the low kappa values, is that as a result of the individual approach of the tool, the percentage of 'doesn't apply to me' is often high, resulting in very homogeneous samples, causing low kappa values $[11,12,22]$.

Although the reliability of the individual items of the baseline questionnaire is fair to moderate, the ICC between the PBI of the test and retest was 0.77 , which is acceptable. This means that even though not all participants are very consistent in their choice of goals, this does not lead to very deviating PBI-scores. This could be explained by the fact that many people differ only in a few goals between test and retest and that there exist moderate to strong correlations between the achievement of many goals (data not shown).

The reliability of the follow-up questionnaire is better than the baseline with a mean weighted kappa of 0.51 .
Participants were probably in a more stable situation during follow-up, although we have not asked whether anything had changed between test and retest. However, the variation between test and retest items on follow-up had more impact on the ICC, which was 0.62 and therefore not satisfactory. The follow-up intra- and inter-rater reliability were similar. This could be caused by having all questions written out at follow-up, leaving less room for variation between interviewers.

From the hypotheses for baseline validity, almost all hypotheses were confirmed. This suggests participants are likely to choose goals which are relevant for them. On the other hand, this is contradicted in the follow-up, where participants often stated that the goal was not applicable for them, for the goal 'washing and dressing' this was even $34 \%$. This could have several causes: first, the P-BAS HOP does not discriminate between preservation and improvement, so the goal could have been to preserve a function, but this is not clear in the questioning, especially through use of the word 'again'. Second, participants may have forgotten in what poor condition they were during admission, therefore ignoring how much 
they have improved. In the literature, this is called response shift or recall bias, and occurs more frequently opposite, so patients underestimate afterwards their condition during admission [23-25]. However, Hinz et al. showed that around 20 to $30 \%$ of the patients afterwards overestimated their condition during admission [24]. A third explanation could be that it is unclear which time period the participants had to compare with: during hospitalisation, for example, participant were unable to wash and dress themselves, but before admission this was not a problem. Compared to the situation at admission it was an improvement, but compared to the situation before, the hospitalisation did not make a difference.

The agreement between goals coded in the open questions and the P-BAS HOP items was $75 \%$, which we considered just valid. This could partly be due to ambiguity: some goals were difficult to code. For example: the goal 'that I can be part of club life' we coded as 'hobbies', but we were not sure what kind of club this participant wanted to be part of and whether this could be seen as a hobby or not. Nevertheless, there were also examples of situations where there was clear disagreement between the goal set by the participant in the open question and the P-BAS HOP. For example, a person stated in the open question 'being able to work in the garden' and in the P-BAS HOP the item 'gardening' was marked as 'not applicable'. This could be caused by the first part of the baseline questionnaire where the participant states whether experiencing or expecting limitations regarding that subject. Apparently a subject does not need to be an actual problem or limitations to be a goal.

A limitation of the method of comparing goals in the open question and the P-BAS HOP, is that participants could mention several goals, but we treated the coded goals and the answers in the P-BAS HOP as if they were independent.

For the testing of the validity in the follow-up, we were limited by small sample sizes and the fact that only small numbers of people deteriorated on the Katz-15, EQ-5D or MSPP between baseline and follow-up. Other studies reported higher amounts of deterioration from around one third of the older patients [26-28]. We probably had a selection bias of the most fit patients wanting to participate.

Of the follow-up hypotheses that were tested, one third were rejected, we therefore have to conclude that the validity of the follow-up questions was weak. This could be a result of recall bias, but also because participants did not know which time period they had to compare with. We did not observe difficulties with validity of the follow-up questionnaire in the Three Step Test Interviews (TSTI) during the pilot [4], but this could be due to the fact we did the TSTI at discharge and not when people were back home for several weeks.

Although the validity of the follow-up questionnaire was weak, the PBI could be considered valid, so the sum of the achievement of all goals weighted for their importance gives a good representation of the benefit the participant experienced by the hospital admission. A disadvantage of an anchor-based method is that the conclusion is always dependent on the anchor chosen [17]. Many participants gave an explanation to their answer to the anchor question, and this revealed that the conclusion of how much benefit the participant had, was not always based on the goals achieved, but could also be based on other indicators, for example how kind the hospital staff was.

For the interpretability we constructed cut-off values for relevant benefit, but one should take into account that a cut-off is in reality not an absolute value and could be dependent on the sample [18].

\section{Limitations}

The sample size of the reliability studies was quite low, especially when taking into account the homogenous samples at baseline. Therefore, the confidence intervals around the kappa values were often large. Another result of the homogenous samples at baseline, is that the numbers of the middle categories are quite low, not meeting the criterion of a minimum of 10 cases in the margins [29]. We therefore also computed kappa values for $2 \times 2$ tables, by combining the categories 'doesn't apply/not at all important' with 'somewhat important' and 'quite important' with 'very important'. This showed similar results, although still not all margins had 10 cases (data not shown). At follow-up the problem of the low sample sizes was larger, since only goals that applied were evaluated and some goals were only chosen by a few participants.

Since the P-BAS HOP was administered on paper, interviewers had to manually circle the goals to ask in the second part, based on the subjects indicated as applicable in the first part. This lead sometimes to the omission of a goal by forgetting to circle a goal.

The time between discharge and follow-up was 3 months, which is quite long if patients have to indicate to what extent the hospitalisation helped to achieve the set goals. In the meantime there could be various other factors which have influenced the result and which are difficult to disentangle from the hospital admission.

\section{Conclusions and recommendations}

Although the concept seems promising, the reliability and validity of the P-BAS HOP appeared to be not yet satisfactory in this format. We therefore recommend adapting the P-BAS HOP, subsequently re-evaluating 
the reliability and validity, as follows: modify the first step in which the participant is asked whether experiencing a problem or limitation with a subject, discriminate between prevention, preservation and improvement, and remove the word 'again'. Also reformulate the questions in the follow-up questionnaire or make clear to which time frame they refer. A good instruction and supervision of the interviewers appeared to be very important to reduce variability between interviewers. Finally, a computer assisted system could reduce missing values.

\section{Supplementary Information}

The online version contains supplementary material available at https://doi. org/10.1186/s12877-021-02079-z.

\section{Additional file 1. \\ Additional file 2. \\ Additional file 3. \\ Additional file 4. \\ Additional file 5. \\ Additional file 6.}

\section{Abbreviations}

ADL: Activities of Daily Living; ICC: Intraclass Correlation Coefficient; MIC: Minimal Important Change; MSPP: Maastricht Social Participation Profile; NRS: Numeric Rating Scale; P-BAS HOP: Patient Benefit Assessment Scale for Hospitalised Older Patients; PBI: Patient Benefit Index; ROC: Receiver Operating Characteristic; RSCL: Rotterdam Symptom Checklist; SF-36: 36-Item Short Form Survey Instrument; TSTI: Three Step Test Interviews; VAS: Visual Analogue Scale; VMS: Safety Management Programme

\section{Acknowledgements}

We would like to thank the research assistants for their assistance with the data collection and all study participants for their time and dedication to answer the questions. We would like to thank Daniël Bosold for his help with text editing and Job van der Palen for his statistical advise.

\section{Authors' contributions \\ MJvdK and SEdR designed the study. MJvdK and SEdR were responsible for the data collection. MJvdK participated in the data collection, supervised the research assistants and performed the statistical analyses. MJvdK wrote the first draft of the manuscript, GJD and SEdR contributed significantly to subsequent manuscript revisions. All authors have read and approved the final version of the manuscript.}

\section{Funding}

This study was funded by an unrestricted grant from the University of Groningen.

\section{Availability of data and materials}

The datasets used and/or analysed during the current study are available from the corresponding author on reasonable request.

\section{Ethics approval and consent to participate}

This study was presented to the Medical Ethics Research Committee of the UMCG (file number M16.192615) and the committee confirmed that the Medical Research Involving Human Subjects Act did not apply to the research project. Official approval by the committee was therefore not required.

All participants gave written informed consent to participate in the study. The study was conducted according to the guidelines of the Declaration of Helsinki.

\section{Consent for publication}

Not applicable.

\section{Competing interests}

The authors declare that they have no competing interests.

\section{Author details}

${ }^{1}$ University of Groningen, University Medical Center Groningen, University Center for Geriatric Medicine, Hanzeplein 1, 9700, RB, Groningen, The Netherlands. ${ }^{2}$ University of Groningen, University Medical Center Groningen, Department of Health Sciences, Applied Health Research, Groningen, The Netherlands. ${ }^{3} \mathrm{NHL}$ Stenden University of Applied Sciences, Research Group Living, Wellbeing and Care for Older People, Leeuwarden, The Netherlands. ${ }^{4}$ Medical Spectrum Twente, Medical School Twente, Enschede, The Netherlands.

Received: 16 November 2020 Accepted: 19 January 2021

Published online: 01 March 2021

\section{References}

1. Boyd C, Smith CD, Masoudi FA, Blaum CS, Dodson JA, Green AR, et al. Framework for decision-making for older adults with multiple chronic conditions: executive summary of action steps for the AGS guiding principles on the Care of Older Adults with multimorbidity. J Am Geriatr Soc. 2019;67(4):665-73.

2. Reuben DB, Tinetti ME. Goal-oriented patient care-an alternative health outcomes paradigm. N Engl J Med. 2012;366(9):777-9.

3. Van der Kluit MJ, Dijkstra GJ, de Rooij SE. Goals of older hospitalised patients: a qualitative descriptive study. BMJ Open. 2019;9(8):e029993.

4. van der Kluit MJ, Dijkstra GJ, van Munster BC, De Rooij S. Development of a new tool for the assessment of patient-defined benefit in hospitalised older patients: the patient benefit assessment scale for hospitalised older patients (P-BAS HOP). BMJ Open 2020;10(11):e038203-2020-038203.

5. Heim N, van Fenema EM, Weverling-Rijnsburger AW, Tuijl JP, Jue P, Oleksik AM, et al. Optimal screening for increased risk for adverse outcomes in hospitalised older adults. Age Ageing. 2015;44(2):239-44.

6. de Haes JC, van Knippenberg FC, Neijt JP. Measuring psychological and physical distress in cancer patients: structure and application of the Rotterdam symptom checklist. Br J Cancer. 1990;62(6):1034-8.

7. Lamers LM, McDonnell J, Stalmeier PF, Krabbe PF, Busschbach JJ. The Dutch tariff: results and arguments for an effective design for national EQ-5D valuation studies. Health Econ. 2006;15(10):1121-32.

8. Laan W, Zuithoff NP, Drubbel I, Bleijenberg N, Numans ME, de Wit NJ, et al. Validity and reliability of the Katz-15 scale to measure unfavorable health outcomes in community-dwelling older people. J Nutr Health Aging. 2014; 18(9):848-54.

9. Mars GMJ. Kempen, Gertrudis I I M, post MWM, Proot I, Mesters I, van Eijk JTM. The Maastricht social participation profile: development and clinimetric properties in older adults with a chronic physical illness. Qual Life Res. 2009; 18(9):1207-18.

10. Aaronson NK, Muller M, Cohen PD, Essink-Bot ML, Fekkes M, Sanderman R, et al. Translation, validation, and norming of the Dutch language version of the SF-36 health survey in community and chronic disease populations. J Clin Epidemiol. 1998;51(11):1055-68.

11. De Vet HCW, Terwee CB, Mokkink LB, Knol DL. Measurement in medicine. A practical guide. 1st ed. Cambridge: Cambridge University Press; 2011.

12. Sim J, Wright CC. The kappa statistic in reliability studies: use, interpretation, and sample size requirements. Phys Ther. 2005;85(3):257-68.

13. Lowry R. VassarStats: website for statistical computation. 1998-2021. http:// vassarstats.net/kappa.html

14. Landis JR, Koch GG. The measurement of observer agreement for categorical data. Biometris. 1977;33(1):159-74.

15. Cohen J. Statistical power analysis for the bahavioral sciences. second ed.: Lawrence Erlbaum Associates; 1988.

16. Terwee CB, Bot SD, de Boer MR, van der Windt DA, Knol DL, Dekker J, et al. Quality criteria were proposed for measurement properties of health status questionnaires. J Clin Epidemiol. 2007;60(1):34-42.

17. Crosby RD, Kolotkin RL, Williams GR. Defining clinically meaningful change in health-related quality of life. J Clin Epidemiol. 2003;56(5):395-407.

18. de Vet HC, Ostelo RW, Terwee CB, van der Roer N, Knol DL, Beckerman H, et al. Minimally important change determined by a visual method integrating an anchor-based and a distribution-based approach. Qual Life Res. 2007;16(1):131-42. 
19. Wettergren L, Kettis-Lindblad A, Sprangers M, Ring L. The use, feasibility and psychometric properties of an individualised quality-of-life instrument: a systematic review of the SEIQoL-DW. Qual Life Res. 2009;18(6):737-46.

20. Aburub AS, Mayo NE. A review of the application, feasibility, and the psychometric properties of the individualized measures in cancer. Qual Life Res. 2017;26(5):1091-104.

21. Ruta DA, Garratt AM, Leng M, Russell IT, MacDonald LM. A new approach to the measurement of quality of life. The Patient-Generated Index Med Care. 1994;32(11):1109-26.

22. Tooth $L R$, Ottenbacher $K J$. The kappa statistic in rehabilitation research: an examination. Arch Phys Med Rehabil. 2004;85(8):1371-6.

23. Ahmed S, Mayo NE, Wood-Dauphinee S, Hanley JA, Cohen SR. Response shift influenced estimates of change in health-related quality of life poststroke. J Clin Epidemiol. 2004;57(6):561-70.

24. Hinz A, Finck Barboza C, Zenger M, Singer S, Schwalenberg T, Stolzenburg $J U$. Response shift in the assessment of anxiety, depression and perceived health in urologic cancer patients: an individual perspective. Eur J Cancer Care. 2011;20(5):601-9.

25. McPhail S, Haines T. Response shift, recall bias and their effect on measuring change in health-related quality of life amongst older hospital patients. Health Qual Life Outcomes 2010;8:7525-8-65.

26. Buurman B, M., Hoogerduijn J, G., de Haan R, J., Abu Hanna A, Lagaay AM, Verhaar $\mathrm{H}$, J., et al. Geriatric conditions in acutely hospitalized older patients: prevalence and one-year survival and functional decline. PLoS One 2011; 6(11):e26951.

27. Lafont C, Gérard S, Voisin T, Pahor M, Vellas B. Reducing "iatrogenic disability" in the hospitalized frail elderly. J Nutr Health Aging. 2011;15(8): 645-60.

28. Zisberg A, Shadmi E, Gur Yaish N, Tonkikh O, Sinoff G. Hospital-associated functional decline: the role of hospitalization processes beyond individual risk factors. J Am Geriatr Soc. 2015;63(1):55-62.

29. Cicchetti DV, Sparrow SS, Volkmar F, Cohen D, Bourke BP. Establishing the reliability and validity of neuropsychological disorders with low base rates: some recommended guidelines. J Clin Exp Neurospychology. 1991;13(2): $328-38$.

\section{Publisher's Note}

Springer Nature remains neutral with regard to jurisdictional claims in published maps and institutional affiliations.

Ready to submit your research? Choose BMC and benefit from:

- fast, convenient online submission

- thorough peer review by experienced researchers in your field

- rapid publication on acceptance

- support for research data, including large and complex data types

- gold Open Access which fosters wider collaboration and increased citations

- maximum visibility for your research: over $100 \mathrm{M}$ website views per year

At $\mathrm{BMC}$, research is always in progress.

Learn more biomedcentral.com/submissions 